\title{
Does oesophageal motor function improve with time after successful antireflux surgery? Results of a prospective, randomised clinical study
}

\author{
L Rydberg, M Ruth, L Lundell
}

\begin{abstract}
Main objective-There is a continuing debate whether motor abnormalities associated with gastro-oesophageal reflux disease (GORD) are primary phenomena or occur as a consequence of repeated injury caused by inflammation. To get new insights into mechanisms involved, patients were studied before and three years after effective and durable reflux control induced by two types of
\end{abstract} fundoplications.

Patients and methods-Thirty three consecutive patients with chronic GORD entered the trial. All patients had a clinical history of GORD assessed symptomatically, endoscopically, and by use of 24 hour pH-metry. Eighteen were randomised to a $180^{\circ}$ semifundoplication (Toupet) and 15 to a total fundic wrap (NissenRossetti). Manometry was done preoperatively, six months, and three years after the operation assessing motor function in defined areas of the tubular oesophagus and lower oesophageal sphincter.

Results-All patients had a proper control of GORD both when objectively and clinically assessed. Postoperatively, the resting tone of the lower oesophageal sphincter was significantly higher in the Nissen-Rossetti group $(p<0.05)$, and the intra-abdominal portion of the lower oesophageal sphincter was of identical length in the two groups. A significant increase in peristaltic amplitude in the middle and distal third of the oesophagus was recorded at long term follow up compared with the preoperative findings $(p<0 \cdot 05)$, but there was no corresponding effect on propagation speed and duration of contraction. However, an increase in peristaltic amplitude and, as a tentative consequence, a significant decrease $(p<0.05)$ in the frequency of primary peristalsis was found only in patients operated on with a total fundic wrap.

Conclusion-Despite adequate and durable reflux control after fundoplication in patients with chronic GORD, no change was found in oesophageal motor function with time. The higher contraction amplitude and decreased frequency of failed primary peristalsis seen in patients having a total fundic wrap were thus most likely due to a mechanical outflow obstruction in the gastro-oesophageal junction. These results could therefore be interpreted in favour of the hypothesis that GORD is pathogenetically linked to a primary defect in oesophageal motor function. (Gut 1997; 41: 82-86)

Keywords: gastro-oesophageal reflux disease; antireflux surgery; fundoplication; oesophageal peristalsis; peristaltic amplitude

Several studies have shown an association between reflux oesophagitis and low resting tone or dysfunction of the lower oesophageal sphincter (occurring either alone or in conjunction with impaired oesophageal peristalsis). ${ }^{1-3}$ Oesophageal transit may thus be retarded in this condition causing a deficient clearance of installed acid into the oesophagus. ${ }^{2-4}$ Whether these motor abnormalities are primary phenomena or occur as a consequence of repeated injury caused by acid reflux induced inflammation is an area of controversy. ${ }^{5-10}$ Very few studies have approached this problem within the framework of a prospective, controlled clinical trial, particularly with a long term follow up. Surgical series have presented data to suggest that motor function improves after fundoplications, in terms of increased peristaltic amplitude and also a decreased percentage of failed primary peristalsis. ${ }^{7-10}$ This implies that fundoplication procedures should be performed before the mean contraction amplitude has fallen below $35 \mathrm{~mm} \mathrm{Hg}$ - that is, before irreversible damage to oesophageal muscle function has occurred. The design of similar studies does, however, not exclude a more simple explanation of the results namely, purely compensatory mechanisms due to mechanical outflow obstruction in the fundoplication area. These issues were evaluated in a prospective, controlled, randomised clinical trial comparing the long term oesophageal motor effects of two different types of fundoplication procedures $\left(360^{\circ}\right.$ total fundic wrap or $180^{\circ}$ partial fundoplication). Both procedures have a documented efficacy in controlling reflux disease ${ }^{11}$ but they exert different mechanical consequences on the gastro-oesophageal junction.

\section{Patients and methods}

Thirty three consecutive patients with chronic gastro-oesophageal reflux disease (GORD), established by symptom evaluation, endoscopy, and 24 hour pH-metry (table 1 ) entered the trial. Four patients had Barrett's oesophagus (columnar lined oesophageal mucosa 
TABLE 1 Patient characteristics, symptoms, and endoscopic findings before and after antireflux surgery

\begin{tabular}{|c|c|c|c|c|}
\hline & \multicolumn{2}{|c|}{ Nissen-Rossetti } & \multicolumn{2}{|l|}{ Toupet } \\
\hline · & Before & After & Before & After \\
\hline $\begin{array}{l}\text { Patients (n) } \\
\text { Mean age (y) (SD) }\end{array}$ & $\begin{array}{l}15 \\
52 \cdot 5(8 \cdot 7)\end{array}$ & 15 & $\begin{array}{l}18 \\
53 \cdot 1(14 \cdot 0)\end{array}$ & 18 \\
\hline Sex ratio $(M / F)$ & $9 / 6$ & & $13 / 5$ & \\
\hline $\begin{array}{l}\text { Mean interval to manometry (months) } \\
\text { Symptoms }(\%) \text { : }\end{array}$ & & $43 \cdot 8$ & & $38 \cdot 6$ \\
\hline \multicolumn{5}{|l|}{ Symptoms $(\%):$} \\
\hline Severe heartburn & 100 & 0 & 89 & 0 \\
\hline Severe acid regurgitation & 27 & 0 & 11 & 0 \\
\hline Dysphagia & 7 & 0 & 2 & 0 \\
\hline \multicolumn{5}{|l|}{ Endoscopy (\%): } \\
\hline Grade 0 & 0 & 100 & 0 & 100 \\
\hline Grade 1 & 13 & 0 & 6 & 0 \\
\hline Grade 2 & 67 & 0 & 83 & 0 \\
\hline Grade 3 & 13 & 0 & 11 & 0 \\
\hline Grade 4 & 7 & 0 & 0 & 0 \\
\hline
\end{tabular}

extending more than $3 \mathrm{~cm}$ above the gastrooesophageal junction), when assessed preoperatively. Eighteen patients were randomised (by use of sealed envelopes) to a Toupet partial fundoplication and 15 had a total fundic wrap according to a modified Nissen-Rossetti technique with complete mobilisation of the fundus. ${ }^{11}$ The two study groups were well matched with respect to disease specificity and other relevant clinical indices (table 1). All operations were done through an abdominal route and the detail of the partial and total fundic wrap techniques have been described elsewhere. ${ }^{11}$

\section{CLINICAL ASSESSMENT}

Each patient was interviewed regarding gastrooesophageal reflux symptoms and symptoms specifically related to the fundoplication procedure by an independent observer at three, six, and 12 months and then yearly after the operations. If not otherwise stated, each symptom was scored from 0 to 3 ( $0=$ no symptoms, $1=$ mild symptoms, $2=$ moderate symptoms, $3=$ severe symptoms). Mild symptoms were defined as those which were easily controlled by dietary measures, occasional intake of antacids, etc. By severe symptoms we meant reflux or postfundoplication symptoms causing considerable discomfort to the patient and requiring continuous medical therapy or other therapeutic interventions.

\section{ENDOSCOPY}

Endoscopic investigation of the oesophagus and the upper gastrointestinal tract was carried out three and 12 months and three years after the operations by use of Olympus video or GIF $\mathrm{XQ}$ endoscopes.

\section{MANOMETRY AND PH-METRY}

Manometry was performed before and at six months and three years after the operations. The pressure characteristics of the gastrooesophageal junction were measured after an overnight fast by water perfused triple lumen pressure catheter with three side holes being positioned $120^{\circ}$ apart. The catheter was connected to a transducer assembly placed at the oesophageal level of the supine subject.
Each channel was perfused at a constant rate of $0.5 \mathrm{ml}$ water per minute via a pneumohydraulic low compliance perfusion pump (Arndorfer Medical Specialities, Green Dale, Wisconsin, USA). A station pull through technique was used and the probe was withdrawn stepwise in $0.5 \mathrm{~cm}$ increments and kept at each level for at least 30 seconds or until the recordings became stable. The high pressure zone was defined as the mean of the highest pressure plateau recorded by each of the three ports minus the mean pressure in the gastric fundus measured at end expiratory state. The length of the intra-abdominal part of the high pressure zone was calculated from the pressure profile as the distance from the point of the first stable pressure rise above the fundus pressure to the first point of negative pressure to occur on inspiration. Standard oesophageal manometry was performed by a single catheter assembly of five polyethylene tubes bound together with five lateral openings placed at 5 $\mathrm{cm}$ intervals from the distal end of the catheter. This catheter was also perfused with water (see above) at a constant rate. The function of the oesophageal body was assessed by placing the proximal side hole one $\mathrm{cm}$ below the upper oesophageal sphincter and the remaining side holes at $5 \mathrm{~cm}$ intervals covering the length of the oesophageal body. This physiological orientation of the measuring device was mandated by the altered pressure characteristics of the gastro-oesophageal junction in the postoperative situation. Ten swallows with $5 \mathrm{ml}$ water at room temperature were made with at least 15 second intervals. The mean contraction amplitude was calculated for the 10 swallows in the distal two segments of the oesophageal body. The peak pressure was measured in relation to the end expiratory intraluminal pressure of the oesophageal body. The time delay between consecutive peaks of the oesophageal contractions was used to calculate the speed of the peristaltic wave. For each contraction, the duration was defined as the length of time in seconds between the intercept points of the steep upstroke and downstroke of the contraction and estimated in relation to the baseline intraluminal pressure. Simultaneous contractions were defined as having a propagation speed of $\geq 20 \mathrm{~cm} / \mathrm{s}$. The frequency of failed primary peristalsis was determined and was characterised as having an amplitude $<10 \mathrm{~mm} \mathrm{Hg}$, as determined at any side hole when the propagated wave induced by water swallow was followed through the oesophagus. All pressure recordings were traced on line on a computerised system (Synectics, Polygram, Stockholm, Sweden, Version $6 \cdot 40$ ). During the postoperative follow up period, 26 patients operated on either with a total fundic wrap or a Toupet fundoplication were also submitted to a manometric investigation using a sleeve sensor. ${ }^{12}$ This manometric tube had side holes again located $5 \mathrm{~cm}$ apart to enable determination of oesophageal body motility responses and a sleeve sensor which was positioned to straddle the gastro-oesophageal junction. Each portion of the catheter assembly was connected to a pressure trans- 
ducer and constantly perfused with water. Ramp pressure, ${ }^{13}$ in this context identical to the intrabolus pressure, was assessed in the distal third of the oesophagus just proximal to the sleeve sensor. It was defined as the plateau pressure ( $\geq 2 \mathrm{~mm} \mathrm{Hg}$ ) above the intraluminal baseline pressure, which was established immediately before the steep up stroke of the peristaltic contraction. The ramp pressure was calculated as the mean pressure level above intraluminal pressure occurring during 10 consecutive water swallows (see above). Twenty four hour pH-metry was carried out preoperatively and during the postoperative follow up at three months and after three years, as previously described. ${ }^{11}$ The patients were ambulatory throughout all recordings and were instructed to follow their usual pattern of living. The $\mathrm{pH}$ data and the information given in the diary cards were evaluated manually as well as by computer.

STATISTICS AND ETHICS

Statistical analyses were carried out with Wilcoxon's signed rank test, Student's $t$ test, and analysis of variance (ANOVA) for repeated measures. All data are presented as means (SD). The study protocol had been approved by the local ethics committee and informed consent to participate in the study was obtained from each patient.

\section{Results}

Table 1 summarises the relevant preoperative and postoperative clinical data. Adequate reflux control was obtained in all patients, with a profound reduction in acid reflux variables in both fundoplication groups at three months as well as at three years after the operations $(p<0.0001)$. No significant differences in 24 hour pH-metry variables were found when the two fundoplication procedures were compared (fig 1). Preoperative lower oesophageal sphincter characteristics were similar in the two study groups and when assessed postoperatively. Lower oesophageal sphincter tone and intra-abdominal length increased significantly $(p<0.05)$ but at six months postoperatively the resting tone of the lower oesophageal sphincter was significantly $(p<0.05)$ higher in those operated on with a Nissen-

TABLE 2 Manometric data for the entire study population before and three years after antireflux surgery

\begin{tabular}{|c|c|c|c|c|}
\hline & \multicolumn{2}{|c|}{ Nissen-Rossetti } & \multicolumn{2}{|l|}{ Toupet } \\
\hline & Before & After & Before & After \\
\hline $\begin{array}{l}\text { Amplitude }(\mathrm{mm} \mathrm{Hg}): \\
\text { Middle } \\
\text { Distal }\end{array}$ & $\begin{array}{l}39.8(18.4) \\
37.5(19.8)\end{array}$ & $\begin{array}{l}56 \cdot 1(17 \cdot 2)^{\star} \\
62 \cdot 3(23 \cdot 3)^{\star}\end{array}$ & $\begin{array}{l}46.9(17.1) \\
50.7(23.4)\end{array}$ & $\begin{array}{l}61 \cdot 1(26 \cdot 6) \\
55 \cdot 6(25 \cdot 7)\end{array}$ \\
\hline $\begin{array}{l}\text { Duration (s): } \\
\text { Middle } \\
\text { Distal }\end{array}$ & $\begin{array}{l}3 \cdot 5(0 \cdot 6) \\
3 \cdot 7(0 \cdot 7)\end{array}$ & $\begin{array}{l}4 \cdot 0(0 \cdot 5) \\
4 \cdot 4(1 \cdot 0)\end{array}$ & $\begin{array}{l}3.4(0.5) \\
3.6(0.8)\end{array}$ & $\begin{array}{l}3.6(0.4) \\
3.8(0.8)\end{array}$ \\
\hline $\begin{array}{l}\text { Propagation speed }(\mathrm{cm} / \mathrm{s}): \\
\quad \text { Middle } \\
\text { Distal } \\
\text { Failed primary peristalsis }(\%) \\
\text { Simultaneous contractions }(\%)\end{array}$ & $\begin{array}{l}3 \cdot 7(1 \cdot 4) \\
4 \cdot 3(1 \cdot 8) \\
14 \cdot 5(19 \cdot 0) \\
11 \cdot 5(5 \cdot 7)\end{array}$ & $\begin{array}{c}3 \cdot 1(0 \cdot 9) \\
3 \cdot 5(1 \cdot 5) \\
4 \cdot 8(10 \cdot 1) \\
13 \cdot 3(30 \cdot 2)\end{array}$ & $\begin{array}{c}3 \cdot 5(1 \cdot 8) \\
4 \cdot 9(3 \cdot 8) \\
5 \cdot 3(10 \cdot 3) \\
12 \cdot 5(26 \cdot 1)\end{array}$ & $\begin{array}{c}4 \cdot 0(2 \cdot 4) \\
3 \cdot 6(2 \cdot 5) \\
6 \cdot 9(10 \cdot 3) \\
12 \cdot 7(28 \cdot 8)\end{array}$ \\
\hline
\end{tabular}

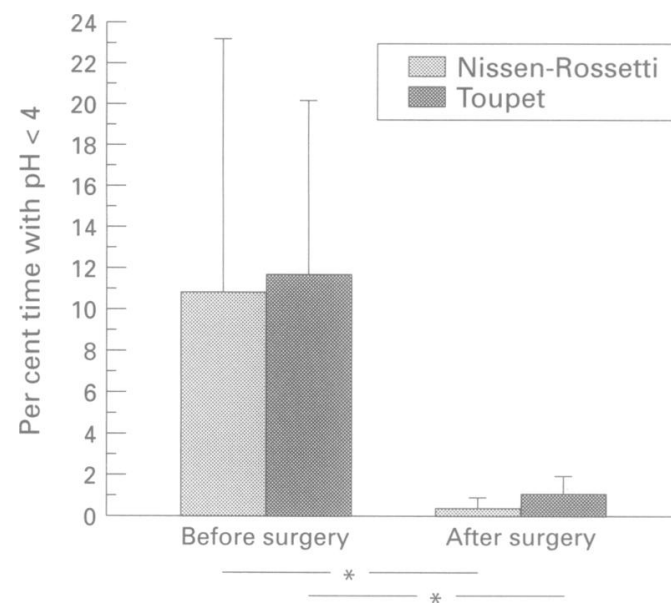

Figure 1: Acid reflux (percentage time $\mathrm{pH}<4$ ) in patients with GORD before and after fundoplication procedures. Values are mean (SD). ${ }^{\star} p<0.05$.

Rossetti total fundic wrap than in the Toupet group (fig 2). The intra-abdominal length of the lower oesophageal sphincter was, however, almost identical in the two groups $(24(4 \cdot 8)$ $\mathrm{mm}$ and $23(4.9) \mathrm{mm}$ in the Nissen-Rossetti and Toupet groups respectively). Table 2 summarises all relevant manometric data recorded preoperatively and postoperatively in the oesophagus. A somewhat, although not significant, lower mean peristaltic pressure amplitude was found preoperatively in those patients who subsequently were allocated to Nissen-Rossetti total fundoplication. Similarly, a non-significant but somewhat higher frequency of failed primary peristalsis was recorded in this group. In total 12 patients had a peristaltic amplitude preoperatively which was less than $35 \mathrm{~mm}$ in the distal oesophagus. When reassessed three years after respective antireflux procedures, the peristaltic amplitude in the middle third of the oesophagus was significantly increased to $58.8(22.6) \mathrm{mm} \mathrm{Hg}$ $(p<0.05$; fig 3$)$. A significant increase $(p<0.05)$ in the peristaltic amplitude was also recorded in the distal third of the oesophaus, but no

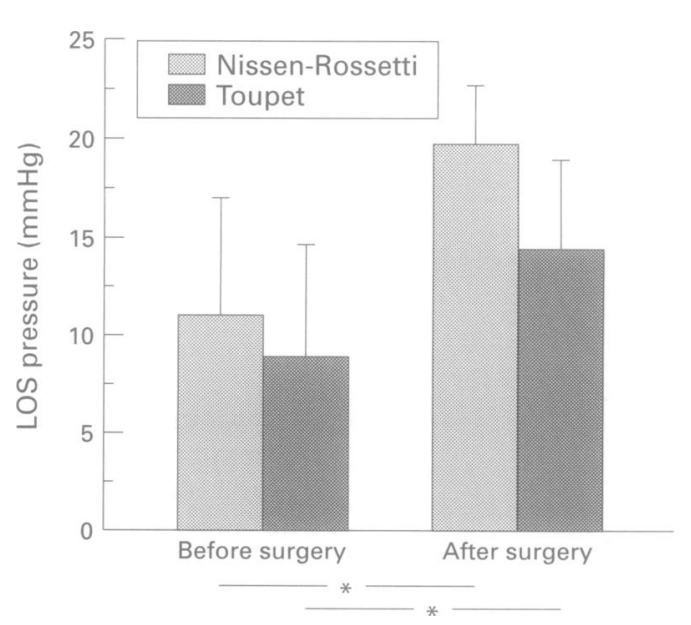

Figure 2: Lower oesophageal sphincter (LOS) pressure measured by station pull through techniques in patients before and six months after a total fundic wrap or a semifundoplication. Values are mean $(S D) .{ }^{*} p<0.05$ 


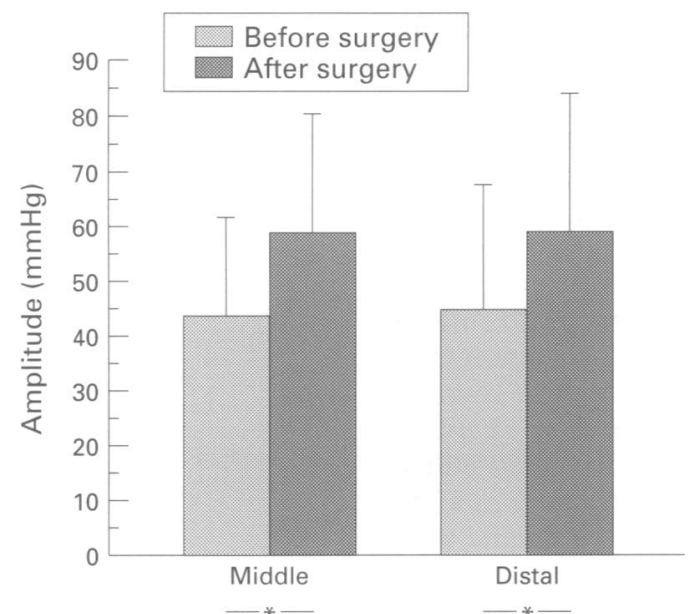

Figure 3: Peristaltic amplitude in the middle and distal oesophagus in patients with GORD before and three years after fundoplication procedures. Values are mean (SD). ${ }^{\star} p<0.05$.

differences were noted either in peristaltic propagation speed nor in the duration of contraction (table 2). When the two fundoplication groups were separately analysed, an increase in amplitude was recorded only in patients operated on with a Nissen-Rossetti fundoplication, whereas relatively unchanged values were recorded in those having a Toupet partial fundoplication (table 2). A significant decrease in the frequency of failed primary peristalsis $(p<0.05)$ was recorded for the entire study group, but again this difference was strictly confined to the patients allocated to a total fundic wrap (table 2). Manometric data from investigations using the sleeve sensor were obtained in 11 patients in the NissenRossetti group and 15 in the Toupet group (mean age $51.4(8.6)$ and $53.7(14.1)$ years respectively). Similar tracings were also obtained at least three years after the actual operative procedures. A standardised mechanical experimental condition was constructed with the sleeve sensor straddling the gastrooesophageal junction allowing the determination of ramp pressure ${ }^{13}$ as has previously been done in the upper oesophageal sphincter. The mean ramp pressure after water swallows was $3.1(3.8) \mathrm{mm} \mathrm{Hg}$ in the Toupet group whereas a somewhat higher value of $3 \cdot 8(4 \cdot 2)$ $\mathrm{mm} \mathrm{Hg}$ was established in those having a total fundic wrap. This difference did, however, not reach significance.

\section{Discussion}

What evidence supports the hypothesis that impaired motor function in GORD occurs as a consequence of reflux induced smooth muscle damage? Experimental studies have shown acid perfusion of the feline oesophagus to produce an inflammatory process which seems to be associated with a reduction in lower oesophageal sphincter pressure. ${ }^{14} 15$ This reduction is reversible and disappears concomitant with the healing of the oesophageal inflammation. In addition, in vitro studies have shown the basal active forces of the circular muscle of the lower oesophageal sphincter to be reduced on acid challenge to the mucosa, a reduction which seems to be dependent on the degree of mucosal injury. ${ }^{16}$ Inflammatory reactions induced by oesophageal acid perfusion tend also to impair the transduction pathway which mediates the contraction of the lower oesophageal sphincter. ${ }^{17}$ However, these injuries have been reported to affect preferentially the lower oesophageal sphincter and not the musculature of the distal oesophagus, an area being equally affected by the inflammatory reaction. ${ }^{16}$ The reasons for this selective injury to the lower oesophageal sphincter are, as yet, unclear. Previous analysis of motor impairment in GORD suggests that the degree of motor dysfunction becomes progressively more severe with advanced grades of oesophagitis. ${ }^{18}$ It is therefore possible that prolonged acid exposure and more profound, transmural and chronic inflammatory processes are factors which induce specific biochemical or biophysical changes in the smooth muscle cells of the tubular oesophagus. Extending and exploring these experimental data to the in vivo situation in human subjects rely on the use of oesophageal manometry, particularly so when experiments have to be repeated over a long time. Oesophageal manometry is the gold standard technique for assessing oesophageal motor function. However, a normal oesophageal function occurs with a wide range of values of peristaltic amplitude, velocity, and duration. This implies that in a specific patient, none of these variables, when expressed as absolute values, will be a valid tool to predict the individual function of the oesophagus. It can, however, be concluded that studies using manometry and carried out during standardised laboratory circumstances are valid, provided that each patient is used as his or her own control before and after specific therapeutic interventions. ${ }^{19}$ Manometric findings in patients before and after a total fundic wrap have reported an increase in the oesophageal peristaltic amplitude with time after the operation with a corresponding reduction in the percentage of contractions having an amplitude $<35 \mathrm{~mm} \mathrm{Hg}{ }^{7}{ }^{10} 20$ Some of these recordings were gained essentially irrespective of the magnitude of the lower oesophageal sphincter tone, implying that the oesophageal motor events did not occur as a consequence of an outflow obstruction in the gastro-oesophageal junction. As we recruited only a few patients with a mean peristaltic amplitude of less than $35 \mathrm{~mm} \mathrm{Hg}$ into our prospective, controlled, randomised clinical trial we cannot specifically consider the question of an eventual motor recovery in this specified clinical setting. In this context it is, however, relevant to re-emphasise the inherited difficulties in interpreting data on lower oesophageal sphincter tone when assessed by station rapid pull through techniques. Apparently this tone varies continuously, albeit to a smaller degree, after fundoplication operations. ${ }^{12} 21$ The question is then raised why an improvement in motor function of the distal oesophagus was not found in Toupet patients 
(partial fundoplication). As previously reported, ${ }^{11}$ and also presently found, total and partial fundoplications are equally durable and control reflux disease equally well. The study groups were also essentially identical with respect to other relevant clinical and laboratory indices. One possible explanation could be that the recorded increase in peristaltic amplitude in the Nissen-Rossetti group occurred solely as a consequence of an outflow obstruction in the gastro-oesophageal junction and therefore should be classified as a secondary phenomenon. The Toupet fundoplication $\left(180^{\circ}\right)$ raises the lower oesophageal sphincter tone to a level which is lower than after a total fundic wrap, despite otherwise similar mechanical consequences on the intra-abdominal length of the high pressure zone. We have previously suggested that these differences in lower oesophageal sphincter tone might explain the occurrence of dysphagia in the early postoperative period after a total fundic wrap. ${ }^{11}$ Giving additional support to the idea of mechanical obstruction in the gastro-oesophageal junction, we found numerically higher ramp pressures in patients having a total fundoplication. Although, our study design and methodology were not specifically focused on this issue, the data would thus imply a higher intrabolus pressure in Nissen-Rossetti operated patients to overcome a subclinical outflow obstruction. As a consequence of a this mechanical situation, an increased amplitude of the peristaltic wave is to be expected which is why it can be argued that the recorded lower frequency of failed primary peristalsis after a total fundic wrap is a quite predictable finding. This is particularly true as we applied a cut off level of $\leq 10 \mathrm{~mm} \mathrm{Hg}$ of the peristaltic amplitude as a criterion for failed primary peristalsis. Our long term findings after successful antireflux surgery, showing no true improvements in oesophageal motor function, are supported by data from studies in which reflux disease is effectively controlled by medical means such as profound acid inhibition therapy. ${ }^{5} 6202223$ The relevance of these findings has also to be considered when applying a broader clinical perspective. The Nissen fundoplication (total fundic wrap) is a widely used surgical procedure to control reflux and it is a generally appreciated operation due to its efficacy. Some troublesome side effects have, however, been reported. ${ }^{24}$ Although our data would support the notion that compensatory mechanisms are operating in these patients to overcome an outflow obstruction in the gastro-oesophageal junction, it can be argued that by making the total fundic wrap shorter, less obstructive consequences would ensue. ${ }^{25}$ The ultimate goal for antireflux surgery is, however, to restore the antireflux mechanisms and thereby normalise the anatomy and physiology of the gastrooesophageal junction without adding adverse effects. At present, a partial fundoplication seems to achieve this goal and therefore has defined theoretical and clinical advantages. ${ }^{26}$ Thus we conclude that long term control of gastro-oesophageal reflux disease by a partial fundoplication is associated with no changes in oesophageal motor function, findings which can be interpreted in favour of the hypothesis that GORD is pathogenetically linked to a primary defect in oesophageal motor function.

1 Gill RC, Bowes KL, Murphy PD, Kingma YL. Esophageal motor abnormalities in gastroesophageal reflux and the effects of fundoplication. Gastroenterology 1986; 91: 364-9.

2 Kahrilas PJ, Dodds WJ, Hogan WJ. Effect of peristaltic dysfunction on esophageal volume clearance. Gastrodysfunction on esophageal

3 Jacob P, Kahrilas PJ, Vanagunas A. Peristaltic dysfunction associated with non-obstructive dysphagia in reflux disease. Dig Dis Sci 1990; 35: 939-42.

4 Maddern GJ, Jamieson GG. Oesophageal emptying in patients with gastro-oesophageal reflux. Br f Surg 1986; 73: 615-7.

5 Timmer R, Breumelhof R, Nadorp JHSM, Smout AJPM. Oesophageal motility and gastro-oesophageal reflux before and after healing of reflux oesophagitis. A study using 24 hour ambulatory $\mathrm{pH}$ and pressure monitoring. Gut 1994; 35: 1519-22.

6 Singh P, Adamopoulos A, Taylor RH, Colin-Jones DG. Oesophageal motor function before and after healing of oesophagitis. Gut 1992; 33: 1590-6.

7 Stein HJ, Bremner RM, Jamieson J, DeMeester TR. Effect of Nissen fundoplication on esophageal motor function. of Nissen fundoplication on

8 Russell COH, Pope CE, Gannan RM, Allen FD, Velasco N, Hill LD. Does surgery correct esophageal motor dysfunction in gastroesophageal reflux? Ann Surg 1981; 194: $290-6$

9 Allen ML, McIntosh DL, Robinson MG. Healing or amelioration of esophagitis does not result in increased lower esophageal sphincter or esophageal contractile pressure. Am $\mathcal{f}$ Gastroenterol 1990; 85: 1331-4.

10 Escandell AO, de Haro LFM, Paricio PP, Albasini JLA, Marcilla JAG, Cuenca GM. Surgery improves defective oesophageal peristalsis in patients with gastrooesophageal reflux. Br f Surg 1991; 78: 1095-7.

11 Lundell L, Abrahamsson H, Ruth M, Sandberg N, Olbe LC. Lower esophageal sphincter characteristics and esophageal acid exposure following partial or $360^{\circ}$ fundoplication: results of a prospective, randomized, clinical study. World f Surg 1991; 15: 115-21.

12 Dent J. A new technique for continue a sphincter pressure measurement. Gastroenterology 1976; 71: 263-71.

13 Cook IJ, Ian J, Gabb M, Panagopoulos V, Jamieson GG, Dodds WJ, et al. Pharyngeal (Zenker's) diverticulum is a disorder of upper esophageal sphincter opening. Gastroenterology 1992; 103: 1229-35.

14 Eastwood GL, Castell DO, Higgs RH. Experimental esophagitis in cats impairs lower esophageal sphincter pressure. Gastroenterology 1975; 69: 146-53.

15 Higgs RH, Castell DO, Eastwood GL. Studies on the mechanism of esophagitis-induced lower esophageal sphincter hypotension in cats. Gastroenterology 1976; 71: 51-7.

16 Biancani P, Barwick K, Selling J, McCallum R. Effects of acute experimental esophagitis on mechanical properties of the lower esophageal sphincter. Gastroenterology 1984; 87: 8-16.

17 Biancani P, Billett G, Hillemeier C, Nissensohn $M$, Rhim BY, Szewczak S, Behar J. Acute experimental esophagitis impairs signal transduction in cat lower esophageal sphincter circular muscle. Gastroenterology 1992; 103: 1199-206.

18 Kahrilas PJ, Dodds WJ, Hogan WJ, Kern M, Arndorfer RC, Reece A. Esophageal peristaltic dysfunction in peptic oesophagitis. Gastroenterology 1988; 91: 897-904.

19 Russell COH, Whelan G. Oesophageal manometry: how well does it predict oesophageal function. Gut 1987; 28: 940-5.

20 De Haro LM, Paricio PP, Escandell MAO, Cuenca GM, Troncoso DV, Tebar JC, Pelegrin VG. Antireflux mechanism of Nissen fundoplication. A manometric study. Scand $₹$ Gastroenterol 1992; 27: 417-20.

21 Ireland AC, Holloway RH, Toouli J, Dent, J. Mechanisms underlying the antireflux action of fundoplication. Gut 1993; 34: 303-8.

22 Timmer R, Breumelhof R, Nadorp JHSM, Smout AJPM Oesophageal motor response to reflux is not impaired in reflux oesophagitis. Gut 1993; 34: 317-20.

23 Howard JM, Reynolds RPE, Frei JV, Flowers ME, McDonald TJ, Tilbe K, Bondy DC. Macroscopic healing of esophagitis does not improve esophageal motility. Dig Dis Sci 1994; 39: 648-54

24 Mughal MM, Bancewic ZJ, Marples M. Oesophageal manometry and $\mathrm{pH}$ recording does not predict the bad results of Nissen fundoplication. Br $\mathcal{F}$ Surg 1990; 77: 43-5.

25 DeMeester TR, Bonavina L, Albertucci M. Nissen fundoplication for gastrooesophageal reflux disease. Evaluation of primary repair in 100 consecutive patients. Ann Surg 1986; 204: 9-20.

26 Lundell L, Abrahamsson $H$, Ruth $M$, Rydberg L, Lönroth $H$, Olbe L. Total fundic wrap (Nissen-Rossetti) or semifundoplication (Toupet) in the surgical treatment of gastrooesophageal reflux disease? Long-term results of a prospective, randomised clinical study. Br f Surg 1996; 83: $830-5$. 